\title{
ÉTICA E TEORIA DAS REPRESENTAÇÕES SOCIAIS: UMA DISCUSSÃO A PARTIR DA CIÊNCIA DA INFORMAÇÃO
}

\author{
Valdir Jose Morigi ${ }^{1}$ \\ valdir.morigi@gmail.com
}

Luis Fernando Herbert Massoni ${ }^{2}$

\section{Resumo}

Reflete sobre o uso acadêmico de informações produzidas pelos cidadãos em ambientes virtuais nas pesquisas de representações sociais. Aborda alguns aspectos éticos relacionados ao uso dessas informações, especialmente no âmbito da Ciência da Informação. Articula os conceitos de informação e representações sociais, de modo a evidenciar o papel das informações na construção das representações. Trata-se de um estudo bibliográfico, com base na literatura da Ciência da Informação. Alega que o uso dessas informações é uma prática ética, desde que os indivíduos produtores não sejam identificados no estudo, de modo a resguardar a fonte. Afirma que o pesquisador é um mediador no tratamento dos dados e deve se assegurar de que seus ideais não orientem a seleção ou exclusão de informações dos resultados do estudo. Conclui que o uso acadêmico da informação produzida pelos cidadãos nos ambientes virtuais implica a necessidade de uma postura ética frente aos sujeitos produtores de informações.

Palavras-chave: Ética na Pesquisa. Representações Sociais. Ciência da Informação. Ambientes Virtuais.

\section{ETHICS AND THEORY OF SOCIAL REPRESENTATIONS:}

\section{A DISCUSSION FROM THE INFORMATION SCIENCE:}

\begin{abstract}
Reflects on the academic use of information produced by citizens in virtual environments in the researches of social representations. It addresses some ethical aspects related to the use of this information, especially in the scope of Information Science. Articulates the concepts of information and social representations, in order to highlight the role of information in the construction of representations. This is a bibliographic study, based on the literature of Information Science. Claims that the use of this information is an ethical practice, as long as the producing individuals are not identified in the study, in order to protect the source. States that the researcher is a mediator in the treatment of data and should ensure that his or her ideals do not guide the selection or exclusion of information from the study results. It concludes that the academic use of information produced by citizens in virtual environments implies the need for an ethical stance towards subjects producing information.
\end{abstract}

\footnotetext{
${ }^{1}$ Mestre em Informação e Comunicação UFRGS e doutorando do Programa de Pós-graduação em Comunicação e Informação (PPGCOM) FABICO/UFRGS.

${ }^{2}$ Doutor em Sociologia pela Universidade de São Paulo (USP). Professor Titular do Departamento de Ciências da Informação, do Programa de Pós-graduação em Comunicação e Informação (PPGCOM) e do Programa de Pós-graduação em Museologia e Patrimônio (PPGMUSPA), da Faculdade de Biblioteconomia e Comunicação (FABICO) da UFRGS. Pósdoutorando no Programa de Pós-graduação em Memória Social/UNIRIO.
}

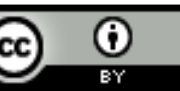

Esta obra está licenciada sob uma Licença Creative Commons Attribution 3.0.

LOGEION: Filosofia da informação, Rio de Janeiro, v. 4 n. 1, p.73-85, Set./ Fev. 2018. 
Keywords: Ethics in Research. Social Representations. Information Science. Virtual Environments.

\section{INTRODUÇÃO}

As representações sociais são fenômenos de ordem social e simbólica, caracterizando-se como formas de ver o mundo. Elas não representam a realidade dos objetos e fatos representados, mas a forma como eles são concebidos por nós. Construídas a partir de nossas interações com o mundo e com os Outros, elas são sempre atravessadas por atos comunicativos, manifestando-se nas nossas práticas informacionais cotidianas. Quando produzimos, comunicamos, utilizamos e/ou nos apropriamos de informações, estamos construindo representações sobre os fenômenos aos quais elas dizem respeito.

As Tecnologias de Informação e Comunicação (TICs) contemporâneas ocasionaram transformações nesse processo, na medida em que os sujeitos sociais ditos "leigos" passaram a ter certa autonomia na produção e circulação de informações em ambientes virtuais. ${ }^{3}$ Nesse sentido, o estudo das representações sociais pode calcar-se na observação e análise de tais informações, pois elas são marcadas pelas concepções de mundo desses sujeitos. Fundamentalmente marcadas pela subjetividade dos seus produtores, essas informações podem até não ser fidedignas, mas seu estudo permite ter acesso às visões de mundo dos cidadãos que as produzem.

No entanto, nas sociedades em mudança, esses processos são atravessados por dilemas éticos. Nesse sentido, o presente estudo visa responder ao seguinte questionamento: De que modo se pode garantir a ética na pesquisa a partir das informações produzidas pelos cidadãos em ambientes virtuais? Propomos uma reflexão teórica que parte da ética na Teoria das Representações Sociais (TRS), com o objetivo de discutir os aspectos éticos implicados nos usos acadêmicos das informações produzidas pelos cidadãos em ambientes virtuais.

O referencial teórico que ampara a presente reflexão parte da TRS, articulando com os estudos de Ciência da Informação e conceitos de informação, pois ela trata da produção, da comunicação, dos usos (apropriações) e das mediações das informações em diferentes contextos sociais. Em um segundo momento, discutimos quais aspectos éticos estão implicados nos usos e apropriações das informações publicadas pelos cidadãos em ambientes virtuais.

\footnotetext{
${ }^{3}$ Cabe ressaltar que as TICs não nos tornaram produtores de informação, na medida em que nós sempre a produzimos. Entendemos que o que mudou foi o fato de que, agora, temos acesso a recursos que nos permitem o compartilhamento dessas informações em maior escala, na medida em que a informação produzida e publicada em ambientes virtuais é mais acessada.
} 


\section{TEORIA DAS REPRESENTAÇÕES SOCIAIS, ÉTICA E INFORMAÇÃO}

O referencial que ampara este estudo está calcado na TRS, de Moscovici (2003), através da qual as representações são concebidas a partir do senso comum, do conhecimento e da comunicação. As representações sociais são visões sobre o mundo, seus objetos e fenômenos e, na concepção do autor, elas são sistemas de valores, ideais e sentidos, sendo que orientamos nossas práticas no mundo material e social a partir delas. Elas se impõem sobre os sujeitos, formando um tipo de realidade, mesmo que formadas pelos seus interesses (MOSCOVICI, 2003). Embora não representem a realidade tal como ela é, elas representam a realidade para os seus sujeitos produtores.

Elas possibilitam a comunicação entre os membros de nossa sociedade, fornecem os códigos que nomeiam e classificam o mundo, bem como as histórias sociais e individuais (MOSCOVICI, 2003). As representações não são apenas conteúdos, mas também estrutura e forma cognitiva, pois se encontram em ligação com os processos simbólicos e ideológicos, especialmente em sua dimensão social (JODELET, 2005). Isso significa que os sujeitos não são indivíduos isolados, mas atores sociais ativos, influenciados pelos aspectos da vida social cotidiana (JODELET, 2009).

É no contato com os outros que são expressas as representações, momento de troca de experiências entre os sujeitos. No entendimento de Jodelet (2009), falar de sujeito no campo das representações sociais é se referir a processos que implicam dimensões físicas e cognitivas e é necessário levar em consideração o nível subjetivo para que possamos compreender uma função importante das representações. Para a autora, o estudo das representações permite acesso aos significados que os sujeitos, sejam individuais ou coletivos, atribuem ao objeto, que é localizado no seu meio social e material.

Estudar representações nos permite compreender os modos como concebemos o mundo e, assim, a nossa própria atuação sobre ele. As representações se explicam quando pensadas a partir de seus contextos específicos de produção, na medida em que as construímos a partir de nossas experiências com o ambiente e com o Outro, em um ato fundamentalmente dialógico. Conforme Jovchelovitch (2004), a produção e a recepção das representações ocorrem por meio de um processo de mediação, configurando uma ação comunicativa.

Esse ato dialógico só é possível através da comunicação, constituída de fluxos informacionais que estruturam e dão sentido às representações. Em outras palavras, nossas práticas informacionais constroem representações sociais, uma vez que as informações as moldam e 
são moldadas por elas. Nesse sentido, ao acessarmos uma informação em qualquer prática cotidiana, estamos acessando uma representação sobre aquilo que é informado.

As representações sociais estão presentes no cotidiano, influenciando as atividades, modos de ser e estar no mundo. Conforme Moscovici (2003), ao serem criadas, elas adquirem vida própria, circulam, se encontram, se atraem e se repelem, dando oportunidade ao nascimento de novas representações, ao mesmo tempo em que antigas morrem. $\mathrm{O}$ fluxo informacional possui alguma similaridade com esse processo, na medida em que, após serem produzidas, perde-se o controle sobre as informações. Elas passam a circular e são mediadas pelos mais variados agentes sociais presentes no cotidiano, que as transformam em notícias, as manipulam, as confrontam com outras informações e, em alguns casos, atuam pela sua obstrução.

O acesso à informação é algo cada vez mais relevante e, conforme Gonzalez de Gómez (2001), ela é um componente principal na construção epistêmica de nossa sociedade. Se a informação é fruto de nossas representações, então entendemos que ela não é imparcial, sendo resultado de seleção, enquadrada de acordo com os interesses de seus sujeitos produtores, influenciada por dinâmicas socioculturais.

A construção de representações sociais ocasionada pelo acesso à informação é permeada por preceitos éticos que precisam estar presentes na postura dos sujeitos que as produzem, mediam e acessam. A respeito da ética, vale lembrarmos:

[...] a palavra vem do grego ethos, que significa modo de ser, carácter; [...] a Ética trata/estuda o que é bom para o indivíduo e para a sociedade, tendo em vista qual a natureza dos deveres na interacção pessoa e sociedade [...]; é teórica, procurando explicar e justificar os costumes de uma sociedade, bem como ajudar na resolução dos seus dilemas mais comuns. (SILVA, 2010, p. 108).

A ética está relacionada ao respeito para com o próximo, entendendo nossos direitos e deveres perante o outro. Assim, ela se manifesta em seu caráter interpessoal, objetivando o bom convívio em sociedade. Enquanto fenômenos expressos em nossas práticas socioculturais e no contato com os outros, as representações sociais são atravessadas pela ética.

Ao refletir sobre a presença da ética na TRS, Marková (2015) afirma que a ética era uma questão pensada mesmo antes da criação da teoria, uma vez que seu autor, Serge Moscovici, há muito ponderava sobre os valores éticos orientadores das crenças na justiça, na busca do progresso e no desejo humano de imortalidade. Segundo a autora, quando Moscovici tomou 
conhecimento das teorias sobre representações coletivas do sociólogo Émile Durkheim ${ }^{4}$, ele se concentrou no fato da ética estar presente em todos os fenômenos sociais.

Em uma abordagem mais dinâmica do que a de Durkheim, Moscovici problematizou em suas discussões os diferentes modos de pensamento (científico, religioso, público, etc.), cada um com valores e padrões éticos distintos (MARKOVÁ, 2015). Ou seja, a ética é um aspecto fundador na TRS, fazendo-se presente de diferentes formas nos variados tipos de conhecimentos presentes na sociedade, uma vez que todo tipo de conhecimento é estruturado em torno de uma ética que lhe dá sentido. Entretanto, salienta Marková (2015) que a TRS não é uma teoria da moralidade ou da ética, mas ela coloca ênfase no ser humano enquanto ser ético, que busca paixões e faz escolhas éticas. Para a autora, é a capacidade - ou disposição para fazer escolhas éticas o que torna humanos os seres humanos.

Uma questão central nessa discussão é o fato de que, se os processos comunicacionais e a informação atuam na construção das representações sociais, então os aspectos éticos pertinentes à produção, mediação e apropriação da informação também precisam ser pensados. Nesse sentido, é necessário avaliar as implicações éticas, os problemas morais, deônticos ou axiológicos próprios ao ato de informar (FREIRE, 2010), caminho que nos leva à discussão sobre a ética da informação:

\footnotetext{
Uma ética da informação diz respeito aos dilemas deônticos ou conflitos morais que surgem na interação entre os seres humanos e as tecnologias e sistemas de comunicação e de informação a fim de refletir e, sobretudo, disciplinar a criação, a organização e o uso das informações. (FREIRE, 2010, p. 7).
}

A importância da ética da informação se sobressai quando pensamos em nosso contexto atual, sendo que, conforme Freire (2010), devemos não apenas formar sujeitos para assimilar ou consumir informação, pois se faz necessário também produzi-la e saber bem utiliza-la. Nesse sentido, o autor defende que uma ética da informação é uma ética para a informação, tratandose de formar (moralmente) o sujeito da informação.

Essa vertente da ética está centralizada em torno da discussão a respeito dos aspectos éticos inerentes às múltiplas apropriações que fazemos dos fluxos informacionais que tecem nossa sociedade. Capurro (2010) se refere à ética intercultural da informação como a relação entre as normas morais universais e as tradições morais locais. Conforme o autor, a reflexão ética se movimenta entre os polos da universalização e a sua concretização em situações singulares.

\footnotetext{
${ }^{4} \mathrm{Na}$ concepção de Durkheim, a ética era um fato social compreendido de forma kantiana e relativamente estático (MARKOVÁ, 2015).
} 
Seria um ponto de convergência entre a ética em sua essencial intercultural e a ética nos contextos locais de sua aplicação.

Os fluxos informacionais contemporâneos que caracterizam o processo de globalização pelo qual passamos explicam o porquê dessa nova interface da ética: vivemos em uma realidade permeada por elementos globais e locais. Conforme Capurro (2010), os conflitos que antes ocorriam em nível local, hoje rapidamente se espalham e tornam-se globais (e vice-versa). Quando trocas tecnológico-culturais ocorrem, há mudanças nas estruturas, sistemas, instituições e normas de informação e comunicação de uma sociedade, produzindo crises e questionamentos na sustentação das relações sociais (CAPURRO, 2010). No seio de todas essas transformações, novos dilemas éticos surgem e precisam ser refletidos.

Ou seja, forma-se uma ética pensada a partir de seus contextos de produção e significação da informação, algo que vai além de uma concepção rígida e imutável de normas a serem seguidas. Trata-se de uma forma de compreender a ética em sintonia com o paradigma social da informação (CAPURRO, 2003), perspectiva que destaca a constituição social dos processos informacionais, em um movimento de inserção dos sujeitos em seus contextos de vida, uma visão mais próxima da fenomenologia.

Isso significa lançar um olhar sociocultural sobre a informação e suas manifestações, tendo em conta as mais variadas práticas informacionais que compõem nossa sociedade. Na visão de Marteleto (1995), a informação é um fenômeno social e simbólico, não sendo pronto e sim construído através do contexto social e da atribuição de sentidos pelos indivíduos que a acessam e produzem. A informação pode salientar certos aspectos em detrimento de outros, afastando-se da ideia de ser uma cópia fidedigna da realidade.

Essas são as concepções teóricas que nos parecem mais adequadas para a reflexão a respeito dos processos éticos que atravessam a construção das representações sociais. Em tal contexto, a informação possui um lugar privilegiado, sendo passível de manipulações e enquadramentos, o que reforça a necessidade de pensarmos as implicações éticas de seu uso, seja em nossas práticas socioculturais ou acadêmicas.

\section{3 ÉTICA E APROPRIAÇÃO DAS INFORMAÇÕES EM AMBIENTES VIRTUAIS}

As representações sociais se expressam através das informações acessadas e produzidas pelos sujeitos. Nesse sentido, a análise de tais informações permite desvendar um pouco das suas concepções de mundo. No âmbito científico, o estudo das representações sociais pode se valer 
dessas informações para dispor de mais uma fonte de materiais para a construção de seu corpus de pesquisa.

Os ambientes virtuais se destacam nesse contexto, na medida em que nossas práticas informacionais foram profundamente transformadas pela sua ascensão, possibilitando aos cidadãos um lugar de destaque na produção de informações. O fácil acesso a elas é outro aspecto facilitador da sua utilização na pesquisa científica, já que se encontram publicadas em ambientes virtuais de fácil acesso, como redes sociais virtuais, aplicativos de celulares, etc. A consulta a essas informações também facilita a operacionalização dos métodos de pesquisa, uma vez que dispensa a realização de entrevistas ou outras técnicas de contato direto com o sujeito pesquisado.

Entretanto, novas ferramentas de pesquisa sempre são acompanhadas de novos dilemas e questionamentos. A interconexão em redes proporcionou um grande potencial comunicacional aos usuários de ambientes virtuais e, como apontam Biscalchin e Almeida $(2011)^{5}$, são construídas novas formas de lidar com a informação, repensadas e apropriadas a partir do contexto sociocultural, o que implica em discussões processuais e de conduta, conduzindo ao debate acerca da ética sobre as fontes e as apropriações informacionais.

No fazer científico, a ética é fundamental na medida em que, conforme Goldim (2016), não é mais possível conceber a ciência como neutra, tendo ela de manter e buscar aprimoramento da sua própria integridade. Para o autor, alguns valores são fundamentais perante a comunidade científica, tais como:

a) Honestidade: refere-se aos dados, resultados e a todas as ações decorrentes da pesquisa;

b) Confiança: presente entre os membros da equipe de pesquisa, na relação entre o pesquisador e o participante da pesquisa, na garantia de confidencialidade das informações e na relação entre a comunidade científica e a sociedade;

c) Justiça: a constatação de uma diferença não deve gerar comportamentos discriminatórios por parte dos cientistas em relação aos pesquisados;

d) Respeito: pesquisador deve ter atitude adequada perante todas as pessoas que se relacionam às atividades de pesquisa;

e) Responsabilidade: intrínseca às ações desempenhadas pelos membros da pesquisa, recaindo principalmente sobre o pesquisador principal.

\footnotetext{
${ }^{5}$ Os autores definem como "netiqueta" o conjunto de regras de conduta que compõem uma etiqueta no uso das TICs por parte do indivíduo.
} 
As discussões éticas no meio acadêmico moldam nossas práticas, mas elas não possuem um tom ortodoxo, uma vez que é necessário refletir sobre a melhor forma de garantir a sua presença nos estudos específicos que realizamos. Nesse viés, Bilcalchin e Almeida (2011) salientam que não convém aplicar mecanicamente os princípios éticos sem considerar as exigências morais e valores específicos de cada atividade.

Em termos de direitos e deveres, a ética se caracteriza pela estipulação de certos limites aos quais devemos respeitar no fazer científico. Para Oliveira (2013), a ética alcança um sentido de restrição, sendo que qualquer agenda ética implica a aceitação de proibições e limites. Para a autora, a questão ética sempre vem à tona no fazer científico, especialmente quando consideramos os avanços pelos quais passou a ciência em virtude do crescente desenvolvimento tecnológico. Ter uma postura ética na pesquisa significa a observação desses aspectos, orientando-se pelo bom senso nas opções metodológicas que norteiam nossos estudos.

Quando pensamos em ética na pesquisa, a situação que vem em mente é o contato direto com seres humanos - às vezes interferindo diretamente em seus corpos, como é o caso de pesquisas com células-tronco, que além de questões éticas, envolvem questões morais e religiosas. Entretanto, não é apenas quando há contato direto com o sujeito pesquisado que a ética deve se fazer presente, e é nesse sentido que destacamos a ética que deve permear o uso da informação produzida pelo cidadão.

Partindo-se da premissa de que a informação é um fenômeno social, entende-se que os processos que a envolvem também requisitam um estatuto que seja permeado por um conjunto de padrões éticos, sobretudo quando se discute a democratização e o acesso aos conteúdos informacionais. (OLIVEIRA, 2013, p. 3-4).

Aplicando esses princípios no estudo das representações sociais a partir das informações produzidas pelos cidadãos, levantamos alguns questionamentos: Até que ponto é ético fazer uso de tais informações na pesquisa científica? Os sujeitos produtores dessas informações devem ser identificados, levando em conta que são autores dos materiais coletados? Como devemos proceder na etapa de tratamento desses materiais? Há questões relacionadas à privacidade que não podem ser desconsideradas quando da apropriação de tais informações pelo método científico.

O sujeito pesquisador inserido no paradigma pós-custodial, conforme Silva (2010), não deve possuir o propósito de fazer apologia do acesso à informação, mas seu interesse deve ser o de 
compreender e explicar as condições contextuais em que ele se processa, bem como os limites e efeitos positivos e negativos. No limite entre a guarda e o acesso à informação, sentencia o autor: "Em última instância, só o pleno acesso é ético, salvaguardado, claro está, o direito ao respeito e ao bom nome de qualquer cidadão. "(SILVA, 2010, p. 121). Aplicando-se esse princípio à discussão ética levantada pelo presente estudo, entendemos que o uso de informações produzidas pelos cidadãos nos estudos de representações sociais não configura uma prática antiética, salvo em casos nos quais haja exposição dos sujeitos produtores da informação.

Pensemos em um exemplo: se estamos realizando um estudo sobre representações sociais sobre a cidade em um ambiente virtual (uma página de alguma rede social virtual, um aplicativo de celular, etc.), identificaremos na coleta dos dados todo tipo de comentários (informações) sobre o ambiente urbano - algumas opiniões atacam frontalmente os direitos humanos, como em manifestações de ódio em relação aos moradores de rua, guardadores de carros, prostitutas, etc. Nos comentários dos cidadãos se expressa o senso comum (cognição social) e algumas formas de preconceito. O senso comum é uma forma irreflexiva - as pessoas expressam suas opiniões sem uma reflexão a respeito. Mediante essas informações, surge a questão: como proceder de maneira ética?

De acordo com Silva (2010), as técnicas e opções metódicas selecionadas devem assegurar o anonimato dos sujeitos inquiridos (no caso de entrevistas). A partir do exposto pelo autor, entendemos que é adequado citar todas as informações identificadas, mas não indicar os seus autores (usuários dos ambientes virtuais), de modo a resguardar os sujeitos - garantindo o respeito ao "bom nome" dos cidadãos. E isso se aplica a qualquer informação identificada, não apenas às que demonstram preconceitos, na medida em que todos os sujeitos que se manifestam nesses ambientes merecem ter suas identidades resguardadas.

Outro aspecto importante a ser considerado no trato com essas informações é a responsabilidade do pesquisador frente ao tratamento dos dados coletados. Isso porque o pesquisador não é apenas um reprodutor: entre a coleta dos materiais e a publicação dos resultados do estudo há uma série de etapas. As informações coletadas pelo pesquisador são organizadas (seja de acordo com categorias pré-estabelecidas ou a partir das categorias que surgem a partir dos dados), analisadas no que tange à sua relevância mediante o material como um todo e, a partir dessa análise, o pesquisador seleciona quais informações ele deseja que constem nos resultados do trabalho, bem como o destaque que recai sobre elas. Ou seja, o pesquisador possui um papel enquanto mediador nesse processo. 
As ações de mediação podem ser classificadas como explícitas ou implícitas e, de acordo com Gomes (2014), elas são explícitas quando são diretas e mais evidentes (tanto presenciais como virtuais) e implícitas quando indiretas e menos evidentes, como em ações de representação e organização. Entendemos que o trabalho desenvolvido pelo pesquisador frente aos dados coletados se caracteriza como uma mediação indireta, na medida em que não há o contato efetivo com os sujeitos, apenas o tratamento das informações por eles produzidas. Nesse tipo de mediação, cita Gomes (2014), há aspectos subliminares, pois é dificultada a compreensão da sua natureza mediadora e, portanto, da sua dimensão ética.

A mediação realizada no tratamento dos dados é uma etapa em que podem ser identificadas várias condutas inadequadas, dentre as quais Goldim (2016) cita: a fabricação de dados, o descarte ilícito de dados indesejados, substituindo-os por dados fictícios, o uso consciente de método estatístico equivocado e a distorção consciente de interpretação dos resultados ou conclusões. A esse respeito, cabe realizarmos uma crítica mais contundente, pois essas práticas possuem um alcance maior e mais sério do que apenas a produção e publicação de dados incorretos. No momento em que o pesquisador atua dessa forma, ele abre mão do que deveria ser um compromisso básico da ciência: compreender a realidade dos fenômenos estudados para poder transformá-los e, assim, melhorar a vida de toda a sociedade. No momento em que o pesquisador abre mão desse compromisso em nome de interesses pessoais ou vaidade, a própria importância do seu fazer científico é posta em cheque.

Em termos de mediação da informação, Gomes (2014) salienta que é necessário competência e consciência para intervir de modo a evitar a manipulação, e que isso depende de uma conduta ética por parte do mediador. Levando em conta que o pesquisador é, acima de tudo, um ser humano movido por princípios, interesses e desejos, a manipulação dos dados é algo que precisa ser pensado. Especificamente no trabalho com representações sociais, há a possibilidade de que o pesquisador seja levado pelos seus ideais a destacar ou desconsiderar alguns dados, de modo a interferir em seus resultados, na tentativa de provar a existência de alguma representação que lhe convenha.

A esse respeito, a autora atenta para a necessidade de "[...] adoção de princípios que inibam a censura e o direcionamento do acesso à informação que desconsidere a igualdade de direitos e a liberdade de pensamento" (GOMES, 2014, p. 53). No caso do estudo das representações sociais, o pesquisador deve estar ciente de que as representações identificadas podem ir de encontro aos seus princípios (inclusive, às vezes vão contra direitos humanos básicos) e que isso precisa ser respeitado. Censurar dados é desrespeitar o direito de expressão dos sujeitos estudados e atrapalhar a compreensão do fenômeno em análise, comprometendo os resultados 
da pesquisa em representações sociais. $O$ pesquisador que não respeita a liberdade de pensamento e opinião não está apto a estudar representações sociais. Ao invés da censura, o que se espera é o posicionamento crítico decorrente de uma análise acurada dos materiais coletados.

\section{CONSIDERAÇÕES FINAIS}

À luz da Ciência da Informação, a ética da informação não pode mais ser pensada apenas em suas práticas no campo da comunicação científica, na medida em que ela molda e é moldada pelas nossas representações sobre o mundo, estando presente nas mais variadas práticas socioculturais que compõem nossa sociedade. O fluxo informacional auxilia na construção da cognição social sobre o mundo através das ações comunicativas e dos processos interativos que desenvolvemos uns com os outros.

As informações acessadas e produzidas pelos sujeitos em ambientes virtuais se constituem um importante material para o pesquisador interessado em compreender como os diferentes grupos em contextos diversos constroem as suas representações sociais sobre o mundo (realidade). No atual contexto em que se enfatiza cada vez mais o fluxo livre da informação, dada a intensificação dos usos das TICs, os ambientes virtuais tornam-se fontes de informação privilegiadas para o estudo de diversos temas que estão em pauta na agenda social. Entretanto, fazer uso desses recursos torna necessário assumir uma postura ética em relação ao sujeito e às suas informações, no sentido de proteger a sua privacidade e a confiabilidade dos dados no interior das organizações, garantindo o respeito ao ser humano e a liberdade de opinião e de expressão.

Como argumentamos ao longo desta reflexão, as apropriações das informações dos ambientes virtuais no âmbito acadêmico podem ser uma prática ética, desde que sejam resguardadas as identidades dos sujeitos que as produziram. O papel do pesquisador no tratamento dos dados coletados é assumir uma postura de respeito para com o material coletado, não deixando que suas convicções influenciem na seleção das informações. A manipulação ou censura dos dados coletados não apenas torna equivocados os resultados, como também desvirtua a compreensão adequada dos fenômenos em estudo, prejudicando o real propósito do fazer científico.

Ressaltamos que os aspectos abordados nesse texto trazem alguns dilemas e questões éticas que necessitam ser aprofundadas, pois dizem respeito à prática científica e às condições sociais da produção do conhecimento. Refletimos sobre a questão do tratamento das 
informações produzidas pelos cidadãos e publicadas em ambientes virtuais e seus imperativos éticos, tal como a postura do pesquisador e a ética da informação neste contexto. $O$ tema da ética da informação, seja na pesquisa científica ou nas práticas sociais, é fundamental no campo da Ciência da Informação.

\section{REFERÊNCIAS}

BISCALCHIN, A. C. S.; ALMEIDA, M. A. Apropriações sociais da tecnologia: ética e netiqueta no universo da infocomunicação. InCID, Ribeirão Preto, v. 2, n. 1, p. 193-207, jan./jun. 2011.

CAPURRO, R. Desafíos téoricos y prácticos de la ética intercultural de la información. In: FREIRE, G. H. A. (Org.). Ética da informação: conceitos, abordagens, aplicações. João Pessoa, Ideia, 2010. p. 11-51.

CAPURRO, R. Epistemologia e Ciência da informação. In: ENCONTRO NACIONAL DE PESQUISA EM CIÊNCIA DA INFORMAÇÃO, 5., 2003, Belo Horizonte. Anais... Belo Horizonte: ECI/UFMG, 2003.

FREIRE, G. H. A. Sobre a ética da informação. In: (Org.). Ética da informação: conceitos, abordagens, aplicações. João Pessoa, Ideia, 2010. p. 5-10.

GOLDIM, J. R. Integridade na pesquisa: um desafio sempre atual. In: PITHAN, L. H.; BARCELLOS, M. L. L. Integridade na pesquisa e propriedade intelectual na universidade. Porto Alegre: EDIPUCRS, 2016.

GOMES, H. F. A dimensão dialógica, estética, formativa e ética da mediação da informação. Informação \& Informação, Londrina, v. 19, n. 2, p. 46-59, 2014.

GONZÁLEZ DE GÓMEZ, M. N. Para uma reflexão epistemológica acerca da Ciência da Informação. Perspectivas em Ciência da Informação, Belo Horizonte, v. 6, n. 1, p. 5-18, jan./jun. 2001.

JODELET, D. Introdução. In: Loucuras e representações sociais. Petrópolis: Vozes, 2005. p. 33-58.

JODELET, D. O movimento de retorno ao sujeito e a abordagem das representações sociais. Sociedade e Estado, Brasília, v. 24, n. 3, p. 679-712, set./dez. 2009.

JOVCHELOVITCH, S. Psicologia social, saber, comunidade e cultura. Psicologia \& Sociedade, v. 16, n. 2, p. 20-31, maio/ago. 2004.

MARKOVÁ, I. Ética na Teoria das Representações Sociais. In: JESUÍNO, J. C.; MENDES, F. R. P.; LOPES, M. J. (Org.). As representações sociais nas sociedades em mudança. Petrópolis: Vozes, 2015. p. 80-102. 
Filosofia da Informação

MARTELETO, R. M. Cultura, educação, distribuição social dos bens simbólicos e excedente informacional. Informare, Rio de Janeiro, v. 1, n. 2, p. 11-23, 1995.

MOSCOVICI, S. Representações sociais: investigações em psicologia social. Petrópolis: Vozes, 2003.

OLIVEIRA, D. A. As questões éticas da democratização da informação. Tendências da Pesquisa Brasileira em Ciência da Informação, João Pessoa, v. 6, n. 1, p. 1-11.

SILVA, A. M. A pesquisa e suas aplicações em Ciência da Informação: implicações éticas. In: FREIRE, G. H. A. (Org.). Ética da informação: conceitos, abordagens, aplicações. João Pessoa: Ideia, 2010. p. 106-125. 